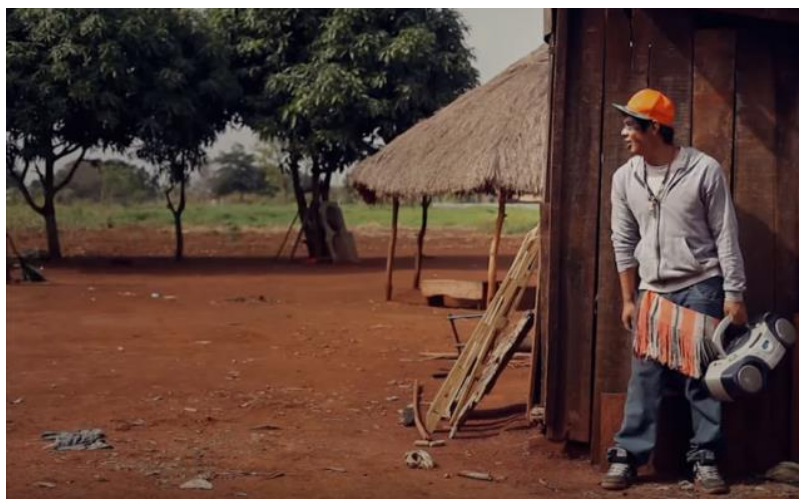

\title{
Aldeias indígenas urbanas: fronteiras discursivas e percursos identitários
}

\section{Urban Indigenous Villages: Discursive Borders and Identity Paths}

\author{
Vânia Maria Lescano Guerra ${ }^{1}$ \\ Laura Cristhina Revoredo Costa ${ }^{2}$
}

\section{Resumo:}

De uma perspectiva discursiva, este artigo tem como objetivo problematizar o percurso identitário dos indígenas, instaurado nos processos de significação dos discursos, a partir das letras das músicas do grupo de rap indígena Brô MC's. Trata-se de entender as mudanças propiciadas pela relação mutual entre os projetos globais e as histórias locais (MIGNOLO, 2003) que atravessam essas formações discursivas (GUERRA, 2015). Os indígenas estão num locus enunciativo latino-americano: a colonialidade impregna os fazeres sociais e culturais e eles ainda carregam consigo os limites de sua constituição como sujeito marginalizado.

Palavras-chave: Discurso. Povos Indígenas. Identidades. Fronteiras.

\section{Abstract:}

From a discursive perspective, this article aims to problematize the identitary path of the Indians established in the processes of signification of the discourses, from the lyrics of the songs of the Indian rap group Brô MC's. It is a question of understanding the changes brought about by the mutual relationship between global projects and local histories (MIGNOLO, 2003) that cross these discursive formations (GUERRA, 2015). The indigenous people are in a Latin American enunciative locus: coloniality pervades social and cultural practices and they still carry with them the limits of their constitution as a marginalized subject.

Keywords: Discourse. Indigenous People. Identities. Borders.

\footnotetext{
${ }^{1}$ Docente do Programa de Pós-graduação em Letras da Universidade Federal de Mato Grosso do Sul (CPTL); Doutora em Linguística pela UNESP de Araraquara, com Pós-doutorado em Linguística Aplicada pela UNICAMP (IEL). E-mail: vguerra1@terra.com.br. Endereço: Av. Eloy Chaves, 298 centro - Três Lagoas (MS) - CEP: 79602-002.

${ }^{2}$ Doutoranda em Estudos Linguísticos na Universidade Federal de Mato Grosso do Sul (UFMS/CPTL), bolsista da CAPES. Mestre em Estudos de Linguagens pela UFMS/CCHS. E-mail: laurakahlil@ hotmail.com. Endereço: Rua Saladino Nunes, 533 - Residencial Oliveira - Campo Grande (MS) - CEP: 79091-664.
} 
É vivendo na fronteira da história e da língua, nos limites de raça e gênero, que estamos em posição de traduzir as diferenças entre eles, numa espécie de solidariedade.

(BHABHA, 2007, p. 238)

\section{Das (situ)ações sociais, culturais e históricas}

O grupo de rap indígena Brô MC's emergiu da justificativa em se transmitir uma ideia de esperança à população indígena Sul-mato-grossense. Composto por Bruno, Charlie, Kelvin e Clemerson, o grupo surge como uma maneira subjetiva de denunciar as situações que enleiam os indígenas e as aldeias (como assaltos, roubos, violências e assassinatos), além de apresentar uma outra cultura indígena aquém do seu território: os indígenas, de etnia Guarani e Kaiowá, buscam demonstrar, através do rap, que a população indígena possui voz, mesmo que embargada, e está em busca de seus direitos.

As letras, em grande maioria, derivam de discursos como consequências de rastros da memória discursiva social. Isto é, há uma determinação no dizer, que é histórica e que intervém irrevogavelmente na relação dos discursos que emergem nas letras das músicas com os saberes e os poderes articulados na sociedade (GREGOLIN, 2003, 2006). Além disso, adquirem corpo tanto em língua portuguesa, quanto em língua guarani, ora a língua espanhola, também deixam suas marcas e, por isso, é uma forma de alcançarem não apenas a população indígena, mas a branca e demais povos latino-americanos. Outras características são perceptíveis nas letras, como, por exemplo, a maneira como as identidades desses jovens estão materializadas nas canções e a vontade de marcar suas identidades como indígenas, no bojo da sociedade hegemônica.

Vale explicar que estamos entendemos a hegemonia como um feixe de esquemas intelectuais e políticos que são vistos pela maioria das pessoas como fornecendo o entendimento natural ou único possível da vida social (SOUZA SANTOS, 2014, p. 33).

O local de enunciação das canções se dá nas aldeias Jaguapiru e Bororo, muito próximas à cidade de Dourados (MS), apesar dos discursos midiáticos e institucionais locais as identificarem como aldeias urbanas. Estas, por sua vez, estão na periferia da periferia da cidade, no estado de Mato Grosso do Sul, sendo entrecortada por uma rodovia com grande movimento. Dourados faz fronteira e está cercada de outros 
estados brasileiros e países latino-americanos, uma vez que é rota para o trânsito entre esses mesmos países. Ressalvamos o fato de que não podemos apenas levar em consideração a fronteira como um ambiente, um local, entre-lugares. Ou seja: ela não configura somente o espaço (in)certo, mas também a produção social cultural, um estado do ser. Por isso seria errôneo verificar a fronteira como um lugar não ambíguo, plural e que merece ser estudado, uma vez que, junto com ela, há elos com outros aspectos culturais, outras forças simbólicas, “(...) todas tentando cavar um lugar junto". (HALL, 2013, p. 29)

Posto isso, a configuração centro/periferia vem suprir o princípio de que a "Periferia não qualifica nem desqualifica um pensamento, mas o situa" (ACHUGAR, 2006, p. 90). Observar o local, no caso a periferia, a aldeia, requer uma visada outra, na qual possa abarcar todas as particularidades que se imbricam nas constituições culturais, históricas e sociais que atravessam os percursos dos sujeitos da fronteira, aqui, corporificado na materialidade musical do grupo de rap indígena.

Uma vez que a liminaridade do espaço-nação é estabelecida e que sua "diferença" é transformada de fronteira "exterior" para sua finitude "interior", a ameaça de diferença cultural não é mais um problema do "outro" povo. Torna-se uma questão da alteridade do povo-como-um. O sujeito nacional se divide na perspectiva etnográfica da contemporaneidade da cultura e oferece tanto uma posição teórica quanto uma autoridade narrativa para vozes marginais ou discursos de minoria. Eles não mais necessitam dirigir suas estratégias de oposição para um horizonte de "hegemonia", que é concebido como horizontal e homogêneo. (BHABHA, 2007, p. 213)

O avanço nos meios tecnológicos ocorridos, especialmente nas últimas décadas, nos meios de comunicação e de interação, proporcionou um maior diálogo e influência com outros povos. Episódio este que, sequencialmente, ativa nossos olhares para esse convívio com outras culturas e propicia uma reflexão acerca do processo de homogeneização e/ou globalização, pois faz aflorar nos discursos as "diferenças e integrações [que] apresentam uma dinâmica própria e as paisagens culturais funcionam em vários múltiplos tempos e direções" (SANTOS, 2008, p.27). Nessa esteira, Anibal Quijano (2005) afirma que a globalização é resultante de uma espécie de método colonial/moderno, iniciado desde o princípio do processo de colonização da América Latina. Acrescenta-se a isso a consolidação do capitalismo como um eixo norteador do discurso de poder, oriundo do padrão patriarcal e eurocêntrico, que resultou na classificação social, racial e religiosa da população latina. 
Em nossa temporalidade, há um grande receio, de caráter nacionalista, de que essas manifestações sejam extintas em decorrência das influências exercidas entre as culturas e os povos. Entretanto, o mesmo receio que promulga uma exaltação cultural, a partir de suas peculiaridades, proporciona também um diálogo intercultural, ocasionando numa releitura cultural, pois "a cultura é tradutória porque essas histórias espacias de deslocamento - agora acompanhadas pelas ambições territoriais das tecnologias 'globais' de mídia - tornam a questão de como a cultura significa" (BHABHA, 2007, p.241). É nesse contexto social e histórico de disseminação de saberes e poderes que entendemos o atravessamento de alteridades e o acontecimento discursivo (des)colonial inscrito nas canções do Brô MC's, a partir dos conflitos, especialmente relacionados à falta de terra e aos massacres desses povos ocorridos no passado.

Tendo em vista o exposto, este artigo $^{3}$ tem como propósito problematizar o percurso identitário dos indígenas instaurado nos processos de significação das formas da linguagem na produção artística do grupo de rap indígena Brô MC's. É necessário salientar alguns elementos que os constituem como sujeitos clivados, sob a justificativa de desconstruir formações ideológicas que são disseminadas e perpetuadas nas relações de poderes hegemônicas. Portanto, não se trata de uma arguição sobre o correto ou errado, mas entender as mudanças propiciadas pela relação mutual entre os projetos globais e as histórias locais (MIGNOLO, 2003) que atravessam as formações discursivas nas letras das músicas dos MC's.

O indígena sul-mato-grossense, mesmo após séculos de colonialidade do saber (QUIJANO, 2005), branca e patriarcal, ainda carrega consigo os limites de sua constituição como sujeito indígena, marginalizado, na medida em que inscreve em seus corpos sua etnia: surge, portanto, indígena, clivado pela identidade jovem, a partir da ideia de que o indígena é um sujeito histórico. Ele está num locus enunciativo latinoamericano: a colonialidade impregna os fazeres sociais e culturais; portanto, se encontra na sobrevida, no bojo da sociedade branca e patriarcal, delineando um percurso identitário subalterno e marginalizado.

O grupo Brô MC's se engaja num ritmo musical também marginalizado e periférico, e não menos desvalorizado, pois sua perspectiva musical surgiu nos guetos

\footnotetext{
${ }^{3}$ Parte da pesquisa financiada pelo $\mathrm{CNPq}$, "O processo identitário do indígena de Mato Grosso do Sul: análise documental e midiática da luta pela terra" (Processo: 471597/2010-4), sob nossa coordenação.
} 
norte-americanos com a finalidade de construir, a partir do grito subalterno, os discursos de resistência. Essa música que se destoa das demais, até da própria periferia, foi consolidada num local de enunciação de histórias locais para o global, a partir da globalização. A fronteira Sul, enquanto locus de enunciação, é o lugar onde as línguas e os dialetos encontram-se na diferença e celebram a transculturalidade desenhada nas canções do grupo. Sabemos que a fronteira é lugar de separação, mas é também local de aproximação das diferenças e semelhanças entre os lugares, sujeitos e suas práticas discursivas. "Se a fronteira, parece circundar algum lugar fechando-o, por uma perspectiva epistêmica preferimos uma visada de que a fronteira é abertura para possibilidades outras: lugares, sujeitos, pensamentos, produções artísticas” (BESSAOLIVEIRA et alii, 2017, p. 17).

\section{Da epistemologia crítica transdisciplinar}

Lo que determina la particularidad del lugar no es la naturaleza sino su historia y su localización em el mundo moderno/colonial; por esta razón ello depende de la importancia que los discursos hegemónicos - que otorgan los privilégios - le hayan otorgado al tiempo y a la historia.

(MIGNOLO, 2003, p. 34)

Num movimento espiralado e nunca fechado em si mesmo, arriscamos dizer que a condição fronteiriça não se vê nem se quer como objeto "ex-ótico" da cultura dominante, "mas como produtora de saberes de múltiplas esferas". Essa visão vem assumindo proporções crescentes "pela conscientização atual de opções outras de conhecimento e de produção artística que não aquelas" (colonialmente ou neocolonialmente) impostas (GOMES, 2017, p. 13). Obviamente, sem que a independência de pensar implique isolamento ou xenofobia, na pretensão equivocada de ignorar a epistemologia moderna e suas derivações.

No caso dos índígenas, ficou reservado a eles um lugar à margem da sociedade, após intensa exploração de sua mão de obra. A partir da consolidação de sua imagem como abandonado e miserável (GUERRA, 2010), o índio - apesar dos focos de resistência que por vezes empreende - tem tal imagem inserida em seu imaginário, uma vez que, de acordo com Coracini (2007, p. 61), o sujeito "se constrói nos e pelos 
discursos imbricados que o vão constituindo" - dentre eles, os discursos do "colonizado", da "escola" e da "mídia": as representações construídas em seu próprio imaginário possuem força suficiente para fazer o indígena acreditar (e não questionar) que a condição em que se encontram é constitutiva de sua identidade, e não uma representação forjada em identidade.

A perspectiva derrideana (2005), ancorada numa leitura crítica, calca-se no descentramento, na Desconstrução dos signos: opera uma de-sedimentação das estruturas binárias, do logocentrismo, da objetividade lógica, em relação à linguagem, sobretudo a escrita, desestabilizando (pré-)conceitos que se esteiam na homogeneização do etnocentrismo. É na busca de uma epistemologia crítica que este trabalho ${ }^{4}$ se inscreve: não se entende o território aqui a partir de um método rigoroso e científico que estabeleça o conjunto de semelhanças e que leva à generalização dos aspectos representacionais em bases da lógica matemática, das ciências físicas, químicas ou biológicas. Não é o método empregado a partir de uma concepção epistemológica de ciência físico-matemática, nem é o método baseado numa epistemologia de ciência social-histórica que define o conhecimento de território, mas sim numa concepção de discurso científico pautado no encontro do ser humano com o mundo.

O território e a identidade, assim, se articulam em uma epistemologia que potencializa seu discurso e noções estruturadoras numa abordagem capaz de auxiliar as pessoas a melhor se localizarem e se orientarem no mundo a partir do lugar em que se encontram. A identidade é, pois, uma construção simbólica e imaginada, mas que se materializa em gestos, ações, posturas e expressões que "naturalizam" e simplificam as diferenças e semelhanças que alguns necessitam para colocar certa ordem idealizada no mundo a partir de suas perspectivas (GUERRA, 2010).

Outro cordão teórico que baliza nossas discussões é o estudo foucaultiano, sobretudo o relativo à perspectiva arqueogenealógica (2006, 2013), com a finalidade de compreender o processo de produção das políticas inclusivas, sob o prisma das relações de saber-poder e do processo de agenciamento das condutas.

Com Foucault (2012), aprendemos que os enunciados ultrapassam os limites linguísticos. Assim, outras formas de registros (uma imagem, o corpo, a voz, o não verbal indissociável do verbal) poderão ser consideradas como um enunciado quando observamos quatro propriedades apontadas pelo filósofo. Em primeiro lugar, deve-se

\footnotetext{
${ }^{4}$ Este estudo integra o Grupo de Pesquisa Interinstitucional "Vozes (In)fames: exclusão e resistência", registrado no CNPq e coordenado pela Profa. Maria José Rodrigues Faria Coracini (IEL-UNICAMP).
} 
analisar como emergem as condições históricas que possibilitaram o surgimento daquele enunciado, ou seja, o seu referencial. A segunda propriedade do enunciado diz respeito ao lugar discursivo a partir de onde se diz o que se diz, em outras palavras, todo enunciado irrompe de determinado espaço onde o indivíduo vem ocupá-lo, constituindo-se como sujeito.

Além disso, amparamo-nos na perspectiva culturalista de Quijano (2005) e de Mignolo (2008) para analisar quais os caminhos que relegaram tais sujeitos aos entrelugares da subalternidade e marginalização.

Depois, temos a característica de que todo enunciado estabelece uma rede de relações com outros enunciados, constituindo seu domínio associado, cujas relações se submetem a regimes de transformação (como de memória, de atualização, modificação, refutação). Temos a singularidade de sua existência material que confere à enunciação seu caráter irrepetível e raro, ainda que tenha alguma base "já dita" com outro enunciado que emergiu noutro momento histórico: os enunciados são esses nós na rede e eles são costurados pelo discurso.

Quando se fala em indígenas no Brasil, emergem, via memória discursiva, alguns dos aspectos que o caracterizaram e continuam a caracterizar de forma emblemática: a questão colonial, a visão dos indígenas como seres de sociedades baseadas em sistemas primitivos, sua inextrincável relação com a natureza, permeado de adornos e pinturas, bem como a condição de aldeados sempre remetida ao fator de isolamento e falta de civilidade (GUERRA, 2010).

A memória, segundo Gregolin (2003, p. 21) “diz respeito às formas significantes que levam uma sociedade a interpretar-se e a compreender-se através dessa interpretação". Portanto, a ideia de memória discursiva é mais ampla e não se refere àquela memória individual. Segundo Guerra (2015), há uma relação entre o discurso e o interdiscurso que nos ajuda compreender o conceito de memória discursiva. Isso porque o discurso se constitui sobre o primado do interdiscurso: todo discurso produz sentidos a partir de outros sentidos já cristalizados na sociedade. Então, pode-se conceber a memória discursiva como sendo esses sentidos já cristalizados, legitimados na sociedade e que são revitalizados e atualizados no intradiscurso. Este é, muitas vezes, apagado pela ideologia, para produzir o efeito de homogeneidade discursiva, espaço de deslocamento, de retomadas, de conflitos, de regularização.

Este trabalho engendra uma perspectiva discursivo-desconstrutivista, o nosso gesto analítico recusa as concepções teóricas mais "em moda", ou como uma 
metodologia pronta que visa à fixidez dos sentidos. "Enquanto "método" de uma perspectiva discursiva, transdisciplinarizar é analisar um enunciado como efeito dos discursos, cuja singularidade só pode ser notada mediante determinadas condições de produção (ou de enunciação)”. (GUERRA; ALMEIDA, 2016)

\section{Um olhar crítico sobre o processo analítico da pesquisa}

Onde e como se produz esse
descentramento como pensamento da
estruturalidade da estrutura? Para
designar esta produção, seria algum
tanto ingênuo referirmo-nos a um
acontecimento, a uma doutrina ou ao
nome de um autor. Esta produção
pertence certamente à totalidade de uma
época, que é a nossa, mas ela já
começou há muito a anunciar-se e a
trabalhar. (DERRIDA, 2002, p.232)

Como já dissemos, os enunciados, as materialidades, têm uma "história", e esta não é apenas um meio de se "saber" o que houve no passado. É, antes de tudo, um dos elementos necessários nos quais podem ser analisadas as produções sociais dos sentidos, uma vez que a história pode ser observada como o efeito das construções discursivas (GREGOLIN, 2006). Por isso não é transparente: é uma interpretação daqueles que tinham o poder de interpretar (DERRIDA, 2001); fato este que motiva um analista a evocar outras noções teóricas que considerem a relação de interpretação estabelecida entre as expressões, e os seus efeitos de sentido. (GUERRA; ALMEIDA, 2016).

Posto isso, verificamos que no primeiro CD desse grupo de jovens indígenas, intitulado "Humildade" , há nove músicas compostas com especificidades étnicas e as línguas os consolidam como produção artística de representação cultural da fronteira, por trazer intrinsecamente a presença da transitoriedade, mesmo no linguajamento, as mobilidades transculturais estão presentes nas condições de produção dos sujeitos do discurso emergidos na fronteira. Para esta análise, recortamos um conjunto de versos da música "Humildade":

As vezes eu me pergunto o que seria de mim

Se eu continuasse assim

Trancado

\footnotetext{
${ }^{5}$ Disponível em https://www.youtube.com/watch?v=bQVLk_mMkMY (acesso em 18 de julho de 2016 às 22 horas)
} 


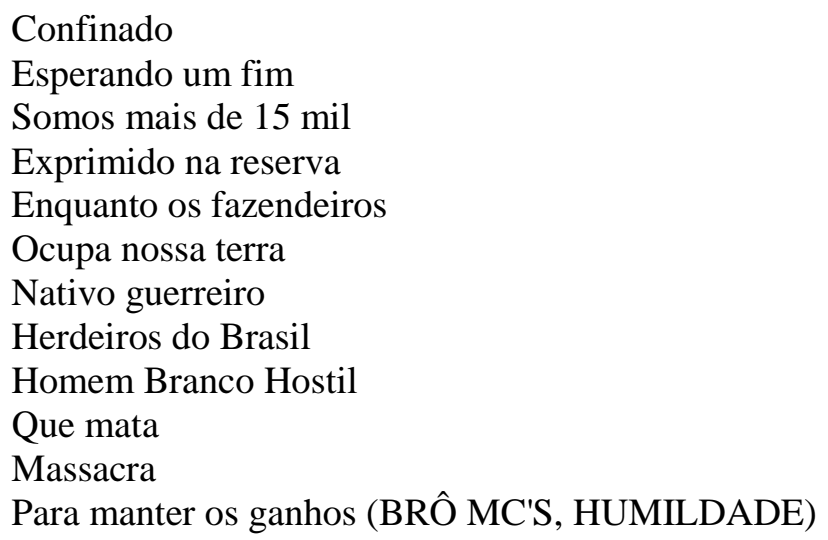

Da perspectiva discursivo-desconstrutivista que adotamos, observamos uma materialidade linguística dos versos das canções, cujos sentidos podem ser (re)lidos como denúncias, vozes embargadas que emergem da memória inscrita nos discursos da "moral, do colonizador, da mídia, da ciência, discurso dentro de discurso, num encadeamento sem fim nem começo" (CORACINI, 2006, p. 01-02); trazendo tanto o discurso de caráter regularizador e disciplinar, quanto imagens marcadas por numa desobediência do sujeito indígena diante de tais discursos normalizadores.

As condições de sobrevida do sujeito indígena manifestam-se como problema logo nas primeiras linhas. No verso "As vezes eu me pergunto o que seria de $\mathrm{mim} / \mathrm{Se}$ eu continuasse assim" em que a conjunção Se, no enunciado, atua como uma interrogação indireta, constituindo a voz de um sujeito que já está numa situação de sobrevivência, condição discursivizada e consolidada pelo outro, indicando incerteza e insegurança, a partir do modo subjuntivo do verbo; a problemaização reside nas condições dessa sobrevida expressa no uso do vocábulo trancado e confinado. Na recuperação da episteme para se ler as condições de produção desses versos, é preciso esclarecer as condições de sobrevivência da população indígena no Mato Grosso do Sul. Como já exposto no princípio deste texto, a população resiste à fome, à miséria e à marginalização cultural e social em aldeias favelizadas, na periferia da periferia, pois se a periferia se constitui por não poder transitar ou estar no centro, a periferia indígena, aqui nessa especificidade, não está nem ao menos no território da cidade de Dourados, está aquém, limitarizada pela rodovia.

Um paradoxo se desenrola tendo em vista que a "sobrevivência não significa mais a morte e o retorno do fantasma, mas a sobrevida de um excesso de vida que resiste ao aniquilamento" (DERRIDA, 2001, p. 78). A maneira como o indígena sulmato-grossense sobreviveu ao longo da história e dos discursos reguladores, disciplinares e concessivos dessa sobrevida anularam algumas especificidades 
identitárias e políticas; esse jogo sensível de pertencimento e não pertencimento é visível tanto em suas práticas culturais e sociais, quanto nas representações do outro. Trata-se de um tipo de sujeitos fronteiriços e periféricos, limitados e debulhados nos excessos dos outros. Esses discursos são o "arquivamento que, além de registrar, produz o acontecimento" (DERRIDA, 2001, p. 24). Desse problema é necessário (re)discutir as cristalizações arquivadas.

Vale dizer que estamos todos atravessados por preceitos, memórias, possíveis verdades e ideologias ancoradas em filosofias positivistas, e que o homem está enredado nas limitações que a inscrição social lhe impõe. E ao evocar a tarefa de estabelecer o ou os sentidos, do ponto de vista de uma (re)organização de regras e de procedimentos que o estruturam, o Discurso hegemônico não pode ser considerado um fenômeno isolado, já que se enquadra em uma variedade de propósitos. Uma discurso materializado linguisticamente num suporte não pode ser (d)escrito e nem apontado como um sistema autônomo, mas, sim, como um percurso de discursos, cujos efeitos de sentidos multifacetados se abrigam em uma memória e a dissimulam (DERRIDA, 2001).

Diante disso, problematizamos que, além do indígena estar trancafiado na angústia patriarcal reguladora, aqui marcada pelo verbo esperar que se encontra flexionado no gerúndio, ele está na condição de espera: o indígena está numa espera contínua, sem fim. Ou seja, ele está enleado nos diversos recursos implícitos de exclusão; e se hoje não há como aniquilá-lo da maneira como foi feito ao longo do processo de colonização do território, o discurso hegemônico surge como colonizador desses saberes e marca a fronteira da exclusão social. Isso porque as aldeias Jaguapiru e Bororo, situadas nos limites da principal rodovia em direção à cidade de Dourados, não possuem infraestrutura básicas, como saneamento, saúde pública, educação e pode-se incluir também o lazer. No entanto, o Estado insiste em dizer que os povos indígenas se encontram em aldeias urbanas.

Entendemos que as identidades desses sujeitos estão permeadas por condições de sobrevida: ora o sujeito se sente pertencido a sua etnia (somos), ora há o incômodo e angústia em poder se ver fora desses arranjos discursivos e disciplinares nos quais o indígena se vê enredado. Ademais, a população indígena do estado de Mato Grosso do Sul vive em aldeias, sem condições básicas para sobrevivência de um ser humano. Isso pode ser denunciado pelo o item lexical reserva, aludindo à preservação que, por sua vez, recorrendo aos sentidos historicamente construídos, compõe o campo semântico do 
salvaguardamento, proteção. Posto isso, os enunciados "Somos mais de 15 mil/ Exprimido na reserva" traz como efeito de sentido de que o indígena, primeiramente, necessita ser preservado, como se pertencesse à natureza, não como o homem branco, mas como um ser sub-humano.

Essas condições sociais e históricas de exclusão e de desigualdade social que permeiam as questões pertinentes à população indígena no Estado atravessam não exclusivamente o caráter do capital, do capitalismo, da colonialidade e do patriarcalismo, mas também estão atreladas ao ruralismo inerente aos interesses políticos e sociais, em que a questão mercadológica é prioridade. O homem branco, representado nas canções, a partir das sensibilidades e memórias dos indígenas, ao longo da história, manifesta um sujeito desenhado ao longo dessa mesma colonialidade, sob o pretexto da opressão e da regulamentação características dos discursos eurocêntricos e hegemônicos. Os versos "Enquanto os fazendeiros/ Ocupa nossa terra" apresentam uma memória discursiva ligada à exclusão nas reservas (além de lar), ao homem branco patriarcal, como um sujeito que ainda hoje é autor de genocídios. A terra aqui versa a relevância dos locais de enunciação indígena: terra não significa um meio para obtenção de capital, trata-se do local da cultura, do lar, do tekoha, em que a memória do (ante)passado está presente.

Um elemento fundamental na construção identitária do indígena, nas letras dos rap do grupo Brô MC's, está ligado à particularidade do pertencimento ou não. A partir da materialidade histórica de tais sujeitos, em analogia ao território e à memória, estes indígenas se encontram atravessados pelos discursos da cultura e do saber indígena que, por sua vez, tem estreita ligação com a terra. Nesse tocante, há uma angústia crítica expressa nos versos "Nativo guerreiro/ Herdeiros do Brasil". Em um gesto analítico dessas expressões, observadas também em outras canções desse grupo de rap indígena, temos o processo identitário do indígena marcado historicamente pela colonialidade, pautada no massacre epistêmico e dos saberes oprimidos, como também no massacre físico (guerras e genocídio) empreendido ao longo desse processo histórico de colonização.

Não visamos a recuperar ou a enunciar qual a melhor identidade, nem ao menos delimitá-la, como índio nativo e com seus direitos resguardados pela origem. Aqui, vale elucidar: despontam os descontentamentos marcados na/pela história. Quem é o herdeiro indígena hoje? O que vão herdar? Os resquícios disciplinares da colonialidade do saber partem do preceito de que não há como retomar ao passado da repressão e da 
opressão, contudo. Isso não nos exime da sensibilidade em observar e poder interpretar no enunciado, "Que mata/ Massacra/ Para manter os ganhos", o percurso identitário do branco patriarcal e opressor ("Homem branco hostil"). Entendemos que essa materialidade, atravessada pelos interdiscursos do colonizador e do patriarcalismo, faz emergir efeitos de sentidos de que os indígenas continuam sendo vítimas dos mesmos opressores capitalistas ao longo da história desses povos na América do Sul.

Segundo Coracini (2011, p.23), a sociedade hegemônica situa os indígenas em "lugares de subalternidade, de submissão, de exclusão: é ela que dita as leis e impõe suas condições [...] é ela que os hospeda (ou os 'hostipeda') ", corroborando o regime de "verdade" de Foucault, em que "cada sociedade tem seu regime de verdade, sua "política geral"” que é produzida por múltiplas coerções, verdadeiros efeitos de poder (FOUCAULT, 2006, p. 12). A autora acrescenta que a verdade histórica a respeito dos indígenas ainda é pouco divulgada nas escolas, visto que eles é que deveriam nos hospedar, a nós, pois somos consequência de "uma mistura étnica e cultural ao longo dos séculos. Hoje, os poucos que restaram não são mais os mesmos, como nós não somos os mesmos, culturas híbridas, complexas, atravessada pelo desejo de consumo da sociedade globalizada" (CORACINI, 2011, p. 24).

Nesse sentido, podemos associar ao termo que Hall (2013) definiu como "comunidade de minorias étnicas", o qual reflete o forte senso de identidade grupal que há entre esses grupos. Ainda que o autor ressalte que esse modelo é uma idealização dos relacionamentos pessoais dos grupos que compõem uma mesma classe, o que significa grupos homogêneos com traços fortes de união e fronteiras bem definidas que separam o mundo exterior,

As chamadas "minorias étnicas" de fato têm formado comunidades culturais fortemente marcadas e mantém costumes e práticas sociais distintas na vida cotidiana, sobretudo nos contextos familiar e doméstico. Elos de continuidade com seus locais de origem continuam a existir (HALL, 2013, p. 72).

Para Mignolo (2008), estamos vivendo a emergência de um outro pensamento, "um pensamento liminar" que aponta para uma razão pós-ocidental. Essa gnose ou pensamento liminar é uma reflexão crítica sobre a produção do conhecimento e implica na sua redistribuição geopolítica até então pautada na colonização epistêmica e na subalternização de todas as formas de saberes que não estivessem pautadas nos cânones da ciência eurocêntrica. A gnose liminar enquanto conhecimento é produzida na 
interseção dos colonialismos modernos e do conhecimento produzido na perspectiva das modernidades coloniais. É uma forma de conhecimento construído nos espaços liminares, nas fronteiras da diferença colonial. É uma poderosa e emergente gnoseologia que, na perspectiva do subalterno, está deslocando e absorvendo as formas hegemônicas do conhecimento. Contudo, não se trata de uma forma de sincretismo ou hibridismo, mas de "um sangrento campo de batalha na longa história da subalternização colonial do conhecimento e da legitimação da diferença colonial" (MIGNOLO, 2003, p. 35). O pensamento liminar na perspectiva da subalternidade é, para Mignolo, uma "máquina para descolonização intelectual e, portanto, para a descolonização política e econômica" (p.76).

Diante disso, na esteira de Sousa Santos, (1997), entendemos que a nossa fronteira não é frontier, é border. A cultura indígena de nosso país é uma cultura de fronteira, "não porque para além de nós se conceba o vazio, uma terra de ninguém, mas porque de algum modo o vazio está do lado de cá, do nosso lado". E é por isso que no nosso (per)curso histórico cultural da modernidade fomos tanto o civilizado como o selvagem, "tanto o colonizador como o emigrante". Essa zona fronteiriça surge híbrida, babélica, lugar em que os contatos se pulverizam e se ordenam segundo micro hierarquias pouco suscetíveis de globalização. Nessa região, são imensas as possibilidades de identificação e de criação cultural, todas igualmente superficiais e igualmente subvertíveis (SOUSA SANTOS, 1997, p. 152-153), especialmente, se considerarmos que vivemos no Mato Grosso do Sul, onde temos as colônias paraguaia, boliviana, nordestina e gaúcha; cada uma com suas singularidades culturais, históricas e políticas.

\section{O que temos, (a)final?}

O processo analítico aponta para um deslocamento do locus de enunciação dos centros do sistema moderno-colonial para suas margens, para as fronteiras das diferentes histórias locais. Mas isso não significa negar a importância da ciência e das formas de saberes ocidentais hegemônicas. Não se trata também de um relativismo cultural e epistêmico, pois aqui não se propõe pensar as diversas histórias, saberes e epistemes locais como simplesmente resultado de diferenças Culturais, mas sim da diferença colonial, resultante da colonialidade do poder e do saber. Isso implica em "regionalizar" e "provincializar" as diferentes histórias locais (modernidades coloniais) 
e os diferentes projetos globais (colonialismos modernos) demonstrando que estes projetos não são universais e abstratos, mas circunscritos nos limites das diferenças coloniais específicas na formação do sistema-mundo moderno colonial. Entendemos com Mignolo (2003) que dessa forma produzimos um exercício de descolonização intelectual que redefine e re-significa nossos horizontes políticos e epistemológicos como intelectuais e como sujeitos históricos.

Nossas reflexões nos levam a pontuar que a hospitalidade, isto é, a aceitação do outro em nossa casa, em nosso país é um imperativo ético e a chance de uma relação pacífica entre os homens. Mais do que isso: a acolhida do outro é a condição da ipseidade, já que não há sujeito sem o reconhecimento do outro. A hospitalidade deve ser incondicional, no sentido derridiano. Não há hospitalidade condicional: se colocamos condições ao outro que vem, ao que chega, não podemos mais falar de hospitalidade. Como resolver, na prática, esse paradoxo? Trata-se de considerar o impossível como "talvez possível", de ter a hospitalidade absoluta como meta a ser buscada apesar de tudo e, nesse sentido, o "impossível" passa a ser condição do "possível". O impossível é a chance do possível, aquilo que mantém aberta a possibilidade. É preciso coragem para sair do lugar, para escolher o que abandonar e o que conservar na viagem, porque sem abandono não há renovação, e sem memória não há História.

No estado do Mato Grosso do Sul, em especial nas áreas de conflito, instauramse inúmeras fronteiras simbólicas, imaginárias, culturais, econômicas e políticas, dinamizando e multifacetando o sentido de identidade. As distâncias entre essas diversas culturas, ou grupos culturais, nesse contexto são necessariamente comprimidas e colocadas em contato. O sentido territorial enquanto lugar fronteiriço aí ascende de importância como entrelugares de vivências, de contatos, de conflitos e de estudos. O trabalho fronteiriço da cultura exige um encontro com "o novo" que não seja parte do continuum de passado e presente. Ele cria uma ideia do novo como ato insurgente de tradução cultural. Essa arte não apenas retoma o passado como causa social ou precedente estético, ela renova o passado, (re)configurando-o como "entrelugares" contingentes que inovam e interrompem a atuação do presente.

Como professores e pesquisadores que somos, tratemos de criar relações nas quais o "outro" não seja transformado no "mesmo", nas quais o "outro" tenha vez e voz. Trata-se de criar relações identitárias construídas na alteridade, em contínua 
transformação em razão da diversidade e da singularidade que abrangem: um lugartempo que é um não lugar-tempo, pois é constituído por um devir intrínseco, por uma exterioridade constitutiva que, ao mesmo tempo, o apaga. Acreditamos que Derrida e Foucault inscrevem o problema do dizer ou escrever como algo que se relaciona com o poder e com a resistência. E as leituras do outro e, consequentemente, nossas interpretações aqui registradas podem ser explicadas na perspectiva de que a leitura como produção de uma escritura se constitui a partir do outro e segundo seu próprio sujeito-leitor enquanto autor.

Por fim, é importante ressaltar que não procuramos, com esta pesquisa, esgotar todas as possibilidades de produção de sentidos e métodos interpretativos distintos, no entanto, nosso objetivo foi contribuir para a percepção da parcialidade dos discursos, de modo a mostrar que o contexto sócio histórico influencia diretamente o processo de construção da identidade do sujeito indígena. Consideramos, acima de tudo, que os resultados de nossa pesquisa não podem ter um fim, mas criar um vínculo de continuidade e de novas visões sobre o sujeito indígena, produzindo pesquisas e reflexões sobre essa temática que tem perpassado a sociedade contemporânea, especialmente no tocante à violência sofrida pelos povos indígenas.

\section{Referências}

ACHUGAR, Hugo. Planetas sem boca: escritos efêmeros sobre arte, cultura e literatura. Trad. Lyslei Nascimento. Belo Horizonte: Editora UFMG, 2006.

BESSA-OLIVEIRA, Marcos A. et alii. Fronteiras Platinas em Mato Grosso do Sul (Brasil/ Paraguai/Bolívia): biogeografias na arte, crítica biográfica fronteiriça, discurso indígena e literaturas de fronteira. Campinas: Pontes, 2017.

BHABHA, Homi K. O local da cultura. Trad. Myriam Ávila, Eliana Lourenço de Lima Reis, Gláucia, Renate Gonçales. Belo Horizonte: Editora UFMG, 2007.

CORACINI, Maria José R. Faria. Pós-modernidade e novas tecnologias no discurso do professor de língua. Revista Alfa de Linguística, São Paulo, 2006, p. 7-21.

Letras, 2007.

A celebração do outro: arquivo, memória e identidade. Campinas: Mercado de

Transdisciplinaridade e análise de discurso: migrantes em situação de rua. Cadernos de Linguagem e Sociedade, 11 (1), 2010, 91-112.

DERRIDA, Jacques. Mal de arquivo: Uma impressão Freudiana. Trad. Cláudia de Moraes Rego. Rio de Janeiro: Relume Dumará, 2001.

A Farmácia de Platão. Trad. Rogério da Costa. São Paulo: Iluminuras, 2005.

FOUCAULT, Michel. A hermenêutica do sujeito. Trad. de Márcio Alves da Fonseca e Salma Tannus Muchail. São Paulo: Martins Fontes, 2006. 
A ordem do discurso. Trad. de Laura F. de Almeida Sampaio. 19. ed. São Paulo: Loyola, 2012.

GOMES, Helois T. Prefácio: Pensamento Fronteiriço: ocupação de espaços, desestabilização de "saberes consagrados". In BESSA-OLIVEIRA, Marcos A. et alii. Fronteiras Platinas em Mato Grosso do Sul (Brasil/ Paraguai/Bolívia): biogeografias na arte, crítica biográfica fronteiriça, discurso indígena e literaturas de fronteira. Campinas: Pontes, 2017, p. 09-16.

GREGOLIN, Maria do Rosário. Sentido, sujeito e memória. Com o que sonha nossa vã autoria. In: GREGOLIN, Maria do Rosário; BARONAS, Roberto (Org.). Análise do discurso: as materialidades do sentido. 2 ed. São Carlos: Clara Luz, 2003.

. Foucault e Pêcheux na análise do discurso: diálogos \& duelos. 2 ed. São Carlos: Claraluz, 2006.

GUERRA, Vania M. Lescano. Práticas discursivas: crenças, estratégias e estilos. São Carlos: Pedro \& João, 2008.

O indígena de Mato Grosso do Sul: práticas identitárias e culturais. São Carlos: Pedro \& João, 2010. UFMS, 2015.

Povos indígenas: identidade e exclusão social. Campo Grande: Editora da

GUERRA, Vania M. L.; ALMEIDA, Willian D. Mulher(es) indígena(s) e escrita(s) de si: a (re)produção das identidades periféricas. In: Povos indígenas em cena: das margens ao centro da história. Campo Grande: OMEP/Brasil, 2017, p. 139-156.

HALL, Stuart. Da diáspora: identidades e mediações culturais. Tradução de Adelaine La Guardia Resende et. all. 2.ed.Belo Horizonte: Editora UFMG, 2013.

MIGNOLO, Walter. Histórias locais / Projetos globais: colonialidade, saberes subalternos e pensamento liminar. Trad. de Solange Ribeiro de Oliveira. Belo Horizonte: Editora UFMS, 2003.

Desobediência epistêmica: A opção descolonial e o significado de identidade em política. In: Cadernos de Letras da UFF. Niteroi, n. 34, 2008. p. 287-324.

NEVES, Maria H, M. Gramática de usos do português. São Paulo: Editora Unesp. 2. ed, 2011.

QUIJANO, Anibal. Colonialidade do poder, eurocentrismo e América Latina. In: LANDER, Edgardo (Org.). A colonialidade do saber: eurocentrismo e ciências sociais. Perspectivas latino-americanas. Ciudad Autónoma de Buenos Aires, Argentina: Clacso, 2005. p. 227-278.

SANTOS, Paulo S, Nolasco dos. Fronteiras do Local: roteiro para uma leitura crítica do regional sul-mato-grossense. Campo Grande: Editora UFMS, 2008.

SOUZA SANTOS, Boaventura de. Se Deus fosse um ativista dos Direitos Humanos. 2 ed. São Paulo: Cortez, 2014.

Cortez, 1997.

Pela mão de Alice: o social e o político na pós-modernidade. São Paulo: 


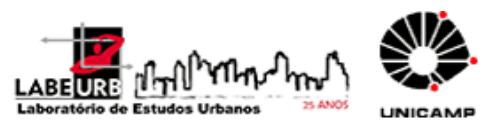

\section{Para citar essa obra:}

GUERRA, Vania Maria Lescano; COSTA, Laura Cristhina Revoredo. Aldeias indígenas urbanas: fronteiras discursivas e percursos identitários. In: RUA [online]. $\mathrm{n}^{\circ}$. 23. Volume 2, p. 335 - 350 - e-ISSN 2179-9911 - Novembro/2017. Consultada no Portal Labeurb Revista do Laboratório de Estudos Urbanos do Núcleo de Desenvolvimento da Criatividade.

http://www.labeurb.unicamp.br/rua/

Capa: Print do vídeo-clipe Koagangua, de Brô $\mathrm{MC}^{\prime}$. Disponível em: https://www.youtube.com/watch?v=IBafJlZxT6s

Laboratório de Estudos Urbanos - LABEURB

Núcleo de Desenvolvimento da Criatividade - NUDECRI

Universidade Estadual de Campinas - UNICAMP

http://www.labeurb.unicamp.br/

Endereço:

LABEURB - LABORATÓRIO DE ESTUDOS URBANOS

UNICAMP/COCEN / NUDECRI

CAIXA POSTAL 6166

Campinas/SP - Brasil

CEP 13083-892

Fone/ Fax: (19) 3521-7900

Contato: http://www.labeurb.unicamp.br/contato 